\title{
(6) \\ Assessing secondhand smoke exposure with reported measures
} OPEN ACCESS

\author{
Erika Avila-Tang, ${ }^{1,2,3}$ Jessica L Elf, ${ }^{2} \mathrm{~K}$ Michael Cummings, ${ }^{4}$ Geoffrey T Fong, ${ }^{5,6}$ \\ Melbourne F Hovell, ${ }^{7}$ Jonathan D Klein, ${ }^{3}$ Robert McMillen, ${ }^{3,8}$ \\ Jonathan P Winickoff, ${ }^{3,9}$ Jonathan M Samet ${ }^{10}$
}

- Additional materials are published online only. To view these files please visit the journal online (http://dx.doi.org/ 10.1136/tobaccocontrol-2011050296).

'Department of Epidemiology, Johns Hopkins Bloomberg

School of Public Health,

Baltimore, Maryland, USA

${ }^{2}$ Institute for Global Tobacco

Control, Johns Hopkins

Bloomberg School of Public

Health, Baltimore, Maryland, USA

${ }^{3}$ American Academy of

Pediatrics Julius B. Richmond

Center of Excellence, Elk Grove

Village, Illinois, USA

${ }^{4}$ Psychiatry and Behavioral

Sciences, Medical University of

South Carolina, Charleston,

South Carolina, USA

${ }^{5}$ Department of Psychology,

University of Waterloo,

Waterloo, Ontario, Canada

${ }^{6}$ Ontario Institute for Cancer

Research, Toronto, Ontario,

Canada

${ }^{7}$ Center for Behavioral

Epidemiology, San Diego State University, San Diego, California USA

${ }^{8}$ Department of Psychology, Mississippi State University, Starkville, Mississippi, USA

${ }^{9}$ Department of Pediatrics,

Massachusetts General

Hospital, Boston,

Massachusetts, USA

${ }^{10}$ Department of Preventive

Medicine, University of

Southern California, Los

Angeles, California, USA

\section{Correspondence to}

Dr Erika Avila-Tang, Institute for Global Tobacco Control, Johns Hopkins Bloomberg School of Public Health, 2213 McElderry St., 4th floor, Baltimore, Maryland 21205, USA: etang@jhsph.edu

Received 28 October 2011 Accepted 29 July 2012

Published Online First

4 September 2012

- http://dx.doi.org/10.1136/ tobaccocontrol-2011-050298

- http://dx.doi.org/10.1136/ tobaccocontrol-2011-050301

- http://dx.doi.org/10.1136/

tobaccocontrol-2012-050698

\section{ABSTRACT}

Non-smokers are exposed to tobacco smoke from the burning cigarette and the exhaled smoke from smokers. In spite of decades of development of approaches to assess secondhand smoke exposure (SHSe), there are still unresolved methodological issues. This manuscript summarises the scientific evidence on the use of SHSe reported measures and their methods, objectives, strengths and limitations; and discusses best practices for assessing behaviour leading to SHSe for lifetime and immediate or current SHSe. Recommendations for advancing measurement science of SHSe are provided. Behavioural measures of SHSe commonly rely on selfreports from children and adults. Most commonly, the methodology includes self, proxy and interview-based reporting styles using retrospective recall or diary-style reporting formats. The reporting method used will vary based upon the subject of interest, assessment objectives and cultural context. Appropriately implemented, reported measures of SHSe provide an accurate, timely and cost-effective method for assessing exposure time, location and quantity in a wide variety of populations.

\section{INTRODUCTION}

In this series of articles, three topic assessments summarising current knowledge about measuring secondhand smoke exposure (SHSe) are presented, covering self-reported measures, environmental measurements and biomarkers, and are based on a multidisciplinary expert meeting held in late 2008 at Johns Hopkins University, Baltimore, USA and supported by the Flight Attendant Medical Research Institute (FAMRI). The meeting addressed SHSe assessment approaches to provide uniform methods for FAMRI investigators and others, and to set the stage for innovation. The topic assessments reflect the course of discussion at the meeting, along with recommendations developed from meeting participants, who were established researchers in one of the three focus areas. This article presents scientific evidence on the use of reported measures of SHSe and their methods, objectives, strengths and limitations; and discusses best practices for assessing behaviour leading to SHSe, via self-report and other measures, for lifetime and immediate or current SHSe. Recommendations for advancing measurement science of SHSe are provided.

\section{MODELS OF EXPOSURE}

The microenvironmental exposure model has been adopted to frame assessments of behaviour leading to SHSe. A microenvironment is a space with a volume (eg, a space in a home, office, school) in which the SHS concentration is 'spatially uniform' during some specific time interval. ${ }^{1}$ The SHS concentration in a microenvironment, at a given time, results from the density of smoking in that environment, mediated by factors diluting or otherwise removing smoke from the air. ${ }^{2}$ SHSe is expressed as the sum of exposures in the multiple microenvironments where a person spends time. ${ }^{134}$

Aspects of the physical and social environments should be considered when developing a measurement tool as both are drivers of smoking and/or SHSe. ${ }^{5}$ Within defined microenvironments, the practices relating to production of $\mathrm{SHSe}$, attenuation, or avoidance of smoke should be assessed over time and by microenvironment. Establishing specific time-activity patterns for the individual in question is important for accurate identification of times and locations of potential exposure. For example, as health-compromised children are likely to spend more time indoors than adults or healthy children, they may be at risk for SHSe. Younger children demonstrating higher hand-to-mouth behaviour may also be exposed to higher SHS residue (ie, 'third-hand smoke') on objects and surfaces. ${ }^{6}$ Collecting parental smoking history, family background, attitudes, family rules about smoking in the home, and social and community standards will lend insight into determinants of SHSe, which likely contribute to smoking behaviour and to whether smoking takes place in the individual's microenvironments, in public and private settings.

\section{ASSESSING SHSE IN DIFFERENT SETTINGS Clinical setting studies}

Interviews or questionnaires administered in clinical settings assist doctors in identifying patients with SHSe who may benefit from counselling or other interventions. SHSe assessment is most important in children, non-smoking adolescents, young adults and in asthmatic populations or among those with chronic obstructive pulmonary disease. Lifetime exposure assessment in adults is critical for risk assessment for lung cancer and coronary heart disease, especially among highexposure workers (eg, flight attendants, bartenders and waiters) and those who have lived with a smoker.

SHSe is generally measured by proxy (parent or other adult) for young and school aged; selfreport for young children; and adolescents. For 
adolescents, the distinction between tobacco use and SHSe from others should be included. Ensuring confidentiality is critical to prevent disclosure of potentially illicit smoking behaviour by teens or their peers to their parents or guardians. SHSe assessment by doctors in a clinical setting, however, is often problematic because clinicians are charged to complete many tasks in a short period. SHSe assessment is not their priority, and they often feel undertrained about intervening in SHSe situations. ${ }^{7}$

\section{Field and epidemiological studies}

Assessing SHSe at the population level requires techniques that can be implemented in large samples. Study needs, however, may be addressed with simple, straightforward approaches if the goals are to measure exposure prevalence. Large populationbased surveys, such as the National Health and Nutrition Examination Survey (NHANES), the Global Youth Tobacco Survey (GYTS), the International Tobacco Control (ITC) Surveys, the Global Adult Tobacco Survey (GATS) and smaller surveys with more focused populations of interest have assessed SHSe in the home and in public places including entertainment venues. Smoking restrictions and bans at home and in the community for microenvironments (eg, restaurants, bars, stores and outdoor environments) are important measures to collect. For example, the GATS, which has been implemented in more than 15 countries, includes detailed questions related about the rules of smoking inside the home and work. The inclusion of these SHSe questions should be guided by local smoke-free practices of the population of interest. These measures can be useful for smoke-free policies' implementation and compliance evaluation and thus be related to respondents as contextual variables in multilevel research designs. ${ }^{8}$

In epidemiological studies, a valid and reliable measurement of SHSe is fundamental to accurately assess disease risk, as inaccurate measurement of a person's exposure can lead to biased risk estimates ${ }^{2}$ and is often cited as a major limitation of studies evaluating association between SHSe and disease. Understanding the nature of the misclassification is critical, as systematic measurement errors can bias risk estimates towards or away from the null, while random errors in exposure misclassification can diminish the exposure-risk relationship. In SHSe studies, where the hypothesised association between exposure and disease is anticipated to be modest, imprecise exposure measurement could lead to a conclusion that a real risk, while modest, does not exist (type 2 error). For SHSe in a population where a large number of people could be affected, even a modest disease risk has important public health implications.

When developing the questionnaire, its method of administration and cultural context for assessing SHSe must be considered. The use of culturally competent instruments and methods will help ensure accuracy by increasing the rate, validity and reliability of the responses. ${ }^{9}$ To maintain reliability and validity, the materials' language, microenvironments and administration must be contextually appropriate. Translated questionnaires should match the original in language, semantics, idioms, experiences and concepts. ${ }^{9}$ Questions about exposure to types of tobacco smoke other than cigarettes should be revised as appropriate.

\section{REPORTED METHODS FOR ASSESSING SHSE}

Questionnaires are the most common method of assessing SHSe because they are simple to administer and cost effective compared to biological markers and environmental monitoring. ${ }^{2}{ }^{10} \mathrm{An}$ added advantage is that individuals can report lifetime SHSe as well as usual and current levels. While some studies also include measures of possible determinants of smoking or exposure behaviour, such as education or working outside of the home, these remain under development. ${ }^{11} 12$

False reporting, or over/under-reporting, are potential limitations of using questionnaires and will vary depending on the cultural context of smoking and SHSe. However, these limitations are not unique to data obtained from questionnaires. For example, if participants switch urine samples to avoid biomarker detection, underascertainment results are similar to false reports of being a non-smoker. Cross-measurement correlations (eg, $\mathrm{r}=$ approximately 0.50 ) show relationships among reported smoking and reported child exposure that are roughly equivalent to 'objective' measures of nicotine or cotinine (a metabolite of nicotine used as a biomarker of $\mathrm{SHSe}$ ), suggesting that no method is error free. ${ }^{13-15}$

A participant's ability to recall SHSe episodes, including frequency and duration, may also be questionable. ${ }^{16}$ Recall accuracy in survey responses can be improved by reducing the timeframe between the discrete event and the length of the recall period $^{16}$; for example, recall over the last $24 \mathrm{~h}$ would be more accurate than over 30 days or 6 months. The assumption, however, that events in the last $24 \mathrm{~h}$ represent a respondent's current experiences may be inaccurate, as that 24 -h period may be atypical. ${ }^{517}$ Researchers need to balance between striving to achieve a respondent's accurate recall and the need to cover a longer period to obtain more representative SHSe estimates. To balance reporting accuracy against research requirements, we recommend a maximum 7-day recall period in a single assessment. However, useful long-term indicators reported with reasonable accuracy can include living with smoking parents, spouse, or other household members.

Another SHSe assessment method is a diary, which can provide participant's detailed exposure information within specific microenvironments. Diaries reduce the recall burden: as reporting occurs over the past day rather than the past week or month, the respondent knows what should be reported in the diary later that day and will likely notice and record instances of exposure as they occur. ${ }^{18}$ Direct observation (live or video recorded) with trained observers can increase objectivity, reducing the rate of false reporting. It is likely to provide more valid data due to focused attention by the trained data collector, whether an individual study participant or a study team member. If used together, diary and observational methods can be quite informative for respondents or microenvironments of particular interest or for providing comparison data to estimate measurement error.

\section{ACCURACY OF OUESTIONS ASSESSING SHSE}

Questions assessing SHSe should be valid and reliable (ie, accurate). Participants' answers to SHSe questions are deemed reliable if those answers are replicated or reproduced when the questions are repeated. ${ }^{19}$ Binary response (ie, yes/no) reliability can be measured using the $\kappa$ statistic (the observed agreement beyond chance), while correlation coefficients can be used for continuous responses. In general, a $\kappa$ value $>0.75,0.40-0.75$ and below 0.40 represents excellent, intermediate to good and poor agreement beyond chance, respectively. ${ }^{19}$ In interpreting Pearson's correlation coefficient, we refer to reliability as: none $(0.0$ to \pm 0.09 ), low ( \pm 0.1 to \pm 0.29 ), moderate ( \pm 0.3 to \pm 0.49 ) and strong ( \pm 0.5 to \pm 1.0 ). Studies testing the validity of SHSe measurement questions assess the questions' ability to correctly identify those individuals truly exposed, along with exposure intensity. ${ }^{19}$ Acceptable 'gold standards' are environmental 
measures, including airborne nicotine or respiratory particles, and biomarkers, such as cotinine. The relationship of the environmental measure with the questionnaire items will vary depending on time since peak exposure, level of continuous versus intermittent exposure, air sampling time frame and measured microenvironments. ${ }^{20} 21$

Respondents may not realise that they have been exposed to SHS. For example, in NHANES 2003-2004, overall self-reported exposure prevalence was underreported as compared to serum cotinine, but the underreporting level depended on the exposure definition. $^{22}$ For instance, $42 \%$ of non-smoking adults had detectable levels of cotinine, while only $5.4 \%$ reported exposure at home and $8.5 \%$ reported exposure at work. For home exposure measurement, one selected family member reported whether any household member smoked anywhere inside the home. SHSe classification at work was based on each participant's response to the number of hours per day that he or she could smell tobacco smoke. ${ }^{22}$ Thus, the specific nature of measures can lead to misclassification in exposure estimates.

To estimate total exposure, the survey respondent should recall and quantify exposure across different locations, length of exposure and its source. Instructing respondents on proper definitions and providing examples of events that qualify, as well as possible SHSe locations, improve recall accuracy. ${ }^{23}$ Surveys intending to capture exposure intensity, estimated time of exposure, number of smokers generating SHS and proximity to smokers should include items addressing these factors specifically. ${ }^{24}$

A comprehensive Medline literature search of Englishlanguage journals was conducted, covering January 1966 to 13 July 2010, and using the search terms 'tobacco smoke pollution (MESH terms) AND questionnaire AND (validat* OR Reproduc* OR reliab*) for studies among humans. Of the 102 articles examined, 3 presented relevant information on questionnaire reliability; 5 others were identified through reference lists of included articles and reviews. A total of 45 validation studies were identified (air nicotine or particulate matter concentrations (13), measurements of hair nicotine (4) and cotinine (28)).

\section{Reliability of questions assessing SHSe}

Adults can reliably answer questions regarding SHSe (yes/no) from their parents during childhood $(\kappa \geq 0.82)$, their spouse, household members, and if they are living with a spouse or mother who smokes (table 1). ${ }^{25-27}$ However, reliability sharply decreases for exposure from father, siblings, own children and other household members. ${ }^{27}$ This includes responses related to years of SHSe to maternal $(r=0.69-0.76)$, paternal $(r=0.75)$ and other household members' smoking $(r=0.63)$ during childhood, as well as for years of exposure by their spouse $(\mathrm{r}=0.95)$ or other household members $(r=0.78)$ during adulthood. ${ }^{26}$ Correlation coefficients ranged from 0.18 to 0.55 for hours per day. ${ }^{26-28}$

Studies of the assessment of children's SHSe have reported good reliability using parents' self-reported smoking behaviour including amount, type of day (weekday/weekend) and place of exposure (table 2). ${ }^{18} 29$ Families of children with asthma $(n=91)$ kept a 2-week diary recording cigarettes per day (CPD) smoked in the home, by type of day, at baseline and 2 months later. ${ }^{18}$ Overall, reliability was high for child's CPD exposed at home per week or during a typical workday, by all sources $(\mathrm{r}=0.81)$ and by the parents $(r>0.75)$. Reliability was lower for parental CPD exposure at home on a typical non-workday $(\mathrm{r}=0.63)$. In another study, high test-retest correlations were obtained for questions about CPD smoked by the mother, total, or at home, either on weekdays or weekends $(r \geq 0.95)$, when again repeatedly at baseline, 3-month and 6-month interview. ${ }^{29}$ Mothers of children with asthma gave highly reliable answers regarding CPD smoked while the child was present in the room or car with smokers $(\mathrm{r}=0.69){ }^{30}$

The reliability of participants' answers to questions about their childhood and adulthood SHSe was compared with surrogates' responses. Surrogates included parents, siblings, spouses, other household members and coworkers. Good agreement was reported between the participants and surrogate responses in nearly all SHSe measures, including presence and number of smokers at home $(r \geq 0.67)$, number of years exposed $(r \geq 0.89)$ and an index of SHSe (severity $\times$ years of exposure) $(\mathrm{r} \geq 0.74) .{ }^{31}$

\section{Validity of questions assessing SHSe using environmental measurements}

The number of smokers or of cigarettes to which non-smokers are exposed may be valid indicators of SHSe intensity (supplementary table S1). Several studies evaluating the correlation between number of cigarettes smoked in the home and air nicotine concentration also found strong correlation coefficients. $^{29} 3233$ Two studies of families of children with asthma, however, reported low or no correlation; both used air nicotine passive monitors. ${ }^{18} 34$ In a study of 254 non-smoking pregnant women wearing air nicotine passive monitors for 1 week, low to moderate correlations were found between total number of smokers or cigarettes to which the women reported exposure in the homes $(0.34-0.35)$ and at work $(r=0.16-0.17) .{ }^{35}$ Strong correlation coefficients were reported for the number of smokers present or to whom the person was exposed at work $(r=0.61-0.67)^{36-38}$ and the number of cigarettes smoked in a restaurant $(\mathrm{r}=0.78)^{36}$ (supplementary table S2).

Two studies validated questions about SHSe intensity among children (supplementary table S3). ${ }^{18} 29$ Correlations between air nicotine measurements and the reported number of cigarettes to which the child (6-17 years old) was exposed and CPD smoked in the house ranged from 0.07 to $0.43 .^{18}$ Responses from mothers of young children were moderately to strongly correlated with air nicotine levels measured with an active monitor. ${ }^{29}$ Strong, nearly identical correlation coefficients were found between the number of cigarettes to which the child was exposed at home from the mother $(r=0.50-0.64)$ and the number of cigarettes smoked inside the home per week by the mother $(r=0.65-0.84) .{ }^{29}$

Several studies have validated questions assessing the duration (hours or minutes) of SHSe using air nicotine concentrations (supplementary tables S1-S3). ${ }^{34} 35373940$ In these studies, the correlations were found non-existent to moderate. As questions about exposure location became more specific, the correlations became weaker. Specifically asking about the number of hours a child is exposed at home yielded low to moderate correlation coefficients in two other studies $(r=0.25-0.36) .{ }^{34} 40$

Coghlin evaluated the validity of a 7-day diary and a questionnaire against air nicotine among 19 non-smoking adults. ${ }^{24}$ The strongest correlations $(\mathrm{r}=0.91-0.95)$ were found with an index based on information about the hours of exposure, number of smokers and their proximity to the participant (supplementary table S4).

\section{Validity of questions assessing SHSe using biomarkers}

Questions regarding children's SHSe and exposure intensity have been validated with the presence of nicotine and cotinine in hair (supplementary table S5). ${ }^{41-44}$ Al-Delaimy et al found that hair nicotine levels in children increased $10.5 \%$ per mother's 
Table 1 Reliability of questions assessing secondhand smoke exposure (SHSe) among adults

\begin{tabular}{l} 
Reference population \\
\hline SHSe status (yes/no) \\
Coultas et al, $1989^{26}: 149$ participants \\
aged $21-79$ years asked $4-6$ months \\
apart asked if the source had smoked \\
daily for $\geq 6$ months \\
Brownson et al, $1993^{25}: 37$ cases and \\
73 controls asked $1.7-1.9$ years apart. \\
All non-smoking women participants of \\
a larger lung cancer study in Missouri.
\end{tabular}

Living with a smoker (yes/no)

Pron et al, 198827: 117 controls

(63 females and 54 males) in a case-control study of lung cancer in Toronto asked 6 months apart

Ass

Assessme

SHSe status

HSe status

Ever living in a house with a regular smoker Living with a regular smoker

Lifetime
Adulthood

$\begin{array}{lll}\text { Pregnancy } & \text { Mother } & \kappa=0.73^{* * *} \\ \text { Childhood } & \text { Mother } & \kappa=0.87^{* *} \\ & \text { Father } & \kappa=0.85^{* * *} \\ \text { Childhood } & \begin{array}{l}\text { Parents } \\ \text { All household } \\ \text { members } \\ \text { Adulthood }\end{array} & \begin{array}{l}\text { Spouse } \\ \text { All household } \\ \text { members }\end{array} \\ & 82.7 \%, \kappa=0.60 ; \mathrm{SE}=0.090 \\ & 83.6 \%, \kappa=0.67 ; \mathrm{SE}=0.095 \\ & 80.0 \%, \kappa=0.59 ; \mathrm{SE}=0.093\end{array}$

$\kappa=0.66$; $S E=0.08$ (females: $\kappa=0.61$; $\mathrm{SE}=0.12$ ) (males: $\kappa=0.70 ; \mathrm{SE}=0.11$ ) $\mathrm{N}=53 ; \kappa=0.89 ; \mathrm{SE}=0.064$

$\mathrm{N}=61 ; \kappa=0.89 ; \mathrm{SE}=0.059$

Wife

Husband

Children

Mother

Father

Sibling

Other (relatives)

Other (non-relatives)

Duration of exposure

Pron et al, 1988 ${ }^{27}$ : 117 controls

(62 females and 53 males) in a

case-control study of lung cancer in

Toronto asked 6 months apart

Coultas et al, 198926: 149 participants aged $21-79$ years asked $4-6$ months apart

Brownson et al, $1993^{25}: 37$ cases and 73 controls asked $1.7-1.9$ years apart. All non-smoking women participants of a larger lung cancer study in Missouri.

Intensity of exposure

Coultas et al, 1989 26 : 149 participants aged $21-79$ years asked $4-6$ months apart. Amount of cigarettes per day respondents were exposed to by the source for $\geq 6$ months.

Pron et al, 1988 ${ }^{27}: 117$ controls

(62 females and 53 males) in a case-control study of lung cancer in Toronto asked 6 months apart Johansson et al, 2005²8: 15 smoking parents asked 2 weeks apart
Years of SHSe

Living with a regular smoker

Years of SHSe

Years of SHSe sharing

the home with smoker(s)

Hours per day of SHSe

Pack-years of SHSe

Categorical cigarettes per day

$(<1,1,>1$ pack/day, or unknown)

No. of smokers living in the home

No. of smokers living in the home
Lifetime

Any

Spouse

Wife

Husband

Parent

Mother

Father

Other (relatives)

Childhood

Mother

Father

Others

Adulthood

Spouse

Other household

members

Childhood

Mother

Father

Others

Adulthood

Spouse

Other household

members

Childhood

All household

members

Parents

Adulthood

All household

members

Spouse

Childhood

Mother

Father

Spouse $\kappa=0.24 ; S E=0.106$

$\kappa=0.76 ; S E=0.103$

$\kappa=0.44 ; \mathrm{SE}=0.077$

$\kappa=0.57 ; \mathrm{SE}=0.117$

$\kappa=0.16 ; S E=0.137$

$\kappa=0.02 ; \mathrm{SE}=0.093$

$\mathrm{r}=0.45 ; 95 \% \mathrm{Cl} 0.29$ to 0.58

(females: $r=0.46 ; 95 \% \mathrm{Cl} 0.24$ to 0.64 )

(males: $r=0.44 ; 95 \% \mathrm{Cl} 0.19$ to 0.63 )

$\mathrm{N}=58 ; \mathrm{r}=0.25 ; 95 \% \mathrm{Cl}-0.01$ to 0.48

$\mathrm{N}=22 ; \mathrm{r}=0.37 ; 95 \% \mathrm{Cl}-0.06$ to 0.68

$\mathrm{N}=36 ; \mathrm{r}=0.20 ; 95 \% \mathrm{Cl}-0.14$ to 0.50

$\mathrm{N}=40 ; \mathrm{r}=0.4895 \% \mathrm{Cl} 0.20$ to 0.69

$\mathrm{N}=8 ; \mathrm{r}=0.69 ; 95 \% \mathrm{Cl}-0.03$ to 0.94

$\mathrm{N}=32 ; \mathrm{r}=0.4695 \% \mathrm{Cl} 0.13$ to 0.70

$\mathrm{N}=17 ; \mathrm{r}=0.59 ; 95 \% \mathrm{Cl} 0.15$ to 0.83

$\mathrm{N}=33 ; \mathrm{r}=0.76$

$\mathrm{N}=57 ; \mathrm{r}=0.75$

$\mathrm{N}=26 ; \mathrm{r}=0.63$

$\mathrm{N}=40 ; \mathrm{r}=0.95$

$\mathrm{N}=67 ; \mathrm{r}=0.78$

$\mathrm{N}=31 ; \mathrm{r}=0.18$

$\mathrm{N}=55 ; \mathrm{r}=0.54$

$\mathrm{N}=20 ; \mathrm{r}=0.51$

$\mathrm{N}=39 ; \mathrm{r}=0.25$

$\mathrm{N}=58 ; \mathrm{r}=0.54$

$60.9 \%, r=0.71$

$73.6 \%, r=0.81$

$52.7 \%, r=0.77$

$60.0 \%, r=0.80$

$\mathrm{N}=48 ; \kappa=0.22^{*}$

$\mathrm{N}=64 ; \kappa=-0.04^{*}$

$\kappa=0.55 ; S E=0.071$ (females: $\kappa=0.52$; $\mathrm{SE}=0.1$ ) (males: $\kappa=0.57$; $\mathrm{SE}=0.1$ )

$r=0.5$
$\mathrm{N}=79 ; \kappa=0.04^{*}$

${ }^{*} \mathrm{p}<0.05 ;{ }^{* *} \mathrm{p}<0.01 ;{ }^{* * *} \mathrm{p}<0.001$.

$\dagger$ Percentage agreement.

$\kappa$, kappa; $r$, correlation coefficient. 
Table 2 Reliability of questions assessing current secondhand smoke exposure (SHSe) among children

\begin{tabular}{|c|c|c|c|}
\hline Reference population & Assessment & Exposure source & Values \\
\hline \multicolumn{4}{|l|}{ Intensity of exposure } \\
\hline $\begin{array}{l}\text { Zakarian et al, } 2004^{29} \text { : mothers with children aged } \leq 4 \text { years } \\
\text { recruited in a randomised controlled trial. The time between } \\
\text { questions was immediate and repeated at baseline, 3-month and } \\
6 \text {-month follow-up. }\end{array}$ & $\begin{array}{l}\text { CPD: asked to report their smoking } \\
\text { on typical days during the past } 7 \text { days }\end{array}$ & Mother & $\begin{array}{l}\text { Weekday: } r=0.97-0.98 \\
\text { weekend: } r=0.95-0.99\end{array}$ \\
\hline $\begin{array}{l}\text { Emerson et al, } 1995^{18}: 91 \text { families with an asthmatic child } \\
6-17 \text { years old asked } 2 \text { months apart }\end{array}$ & CPD smoked at home: diary (2-week period) & Parents & $\begin{array}{l}\text { Workday: } r=0.88 \\
\text { non-workday: } r=0.60\end{array}$ \\
\hline $\begin{array}{l}\text { Zakarian et al, } 2004^{29} \text { : mothers with children aged } \leq 4 \text { years } \\
\text { recruited in a randomised controlled trial. The time between } \\
\text { questions was immediate and repeated at baseline, 3-month and } \\
6 \text {-month follow-up. }\end{array}$ & CPD smoked at home: in the past 7 days & Mother & $r=0.97-0.98$ \\
\hline $\begin{array}{l}\text { Emerson et al, } 1995^{18}: 91 \text { families with an asthmatic child } \\
6-17 \text { years old asked } 2 \text { months apart }\end{array}$ & $\begin{array}{l}\text { Average CPD to which the child is exposed } \\
\text { at home: diary ( } 2 \text {-week period) }\end{array}$ & Not specified & $r=0.84$ \\
\hline \multirow{2}{*}{$\begin{array}{l}\text { Matt et al, } 2000^{23}: 22 \text { mothers of children }<2.5 \text { years old from } \\
\text { an ethnically diverse sample of low-income, low-education } \\
\text { families asked } 2 \text { months apart }\end{array}$} & \multirow{2}{*}{$\begin{array}{l}\text { Weekly no. of cigarettes smoked at home: } \\
\text { in the past } 7 \text { days }\end{array}$} & Mother & $r=0.91$ \\
\hline & & Father & $\mathrm{r}=0.87$ \\
\hline \multirow{4}{*}{$\begin{array}{l}\text { Emerson et al, } 1995^{18}: 91 \text { families with an asthmatic child } \\
6-17 \text { years old asked } 2 \text { months apart }\end{array}$} & Weekly no. of cigarettes smoked at home & Parents & $\mathrm{r}=0.86$ \\
\hline & $\begin{array}{l}\text { No. of cigarettes to which the child is } \\
\text { exposed at home: diary (2-week period) }\end{array}$ & Parents & $\begin{array}{l}\text { Workday: } r=0.82 \\
\text { non-workday: } r=0.63\end{array}$ \\
\hline & \multirow{2}{*}{$\begin{array}{l}\text { Weekly no. of cigarettes to which the } \\
\text { child is exposed at home }\end{array}$} & Parents & $\mathrm{r}=0.76$ \\
\hline & & All smokers & $\mathrm{r}=0.81$ \\
\hline \multirow{4}{*}{$\begin{array}{l}\text { Matt et al, } 2000^{23}: 22 \text { mothers of children }<2.5 \text { years old from } \\
\text { an ethnically diverse sample of low-income, low-education } \\
\text { families asked } 2 \text { months apart }\end{array}$} & \multirow{3}{*}{$\begin{array}{l}\text { Weekly no. of cigarettes to which the } \\
\text { child is exposed at home }\end{array}$} & All sources & $r=0.88$ \\
\hline & & Mother & $r=0.9$ \\
\hline & & Father & $\mathrm{r}=0.81$ \\
\hline & $\begin{array}{l}\text { Weekly no. of cigarettes to which the child } \\
\text { is exposed at home and away from home }\end{array}$ & Parents and others & $r=0.88$ \\
\hline $\begin{array}{l}\text { Hovell et al, } 2002^{30}: 204 \text { children with asthma } 3-17 \text { years old } \\
\text { asked } 5 \text { days apart }\end{array}$ & $\begin{array}{l}\text { No. of cigarettes smoked while the child } \\
\text { was in the same room or car }\end{array}$ & All smokers & $\mathrm{r}=0.69 * * *$ \\
\hline $\begin{array}{l}\text { Zakarian et al, } 2004^{29} \text { : mothers with children aged } \leq 4 \text { years } \\
\text { recruited in a randomised controlled trial. The time between } \\
\text { questions was immediate and repeated at baseline, 3-month and } \\
6 \text {-month follow-up. }\end{array}$ & $\begin{array}{l}\text { No. of cigarettes to which the child } \\
\text { was exposed in the car }\end{array}$ & Mother & $r=0.90-0.93$ \\
\hline
\end{tabular}

${ }^{*} \mathrm{p}<0.05 ;{ }^{* *} \mathrm{p}<0.01 ;{ }^{* * *} \mathrm{p}<0.001$.

†Percentage agreement.

$\mathrm{CPD}$, cigarettes per day; $\kappa$, kappa; $r$, correlation coefficient.

CPD smoked inside the house. ${ }^{41}$ Smaller percentage increases were reported for smoking by the father or other adults. Hair nicotine levels in 112 children were highly correlated with CPD smoked by parents $(r=0.68)$ or by household adults and visitors $(r=0.69)$ inside the house. ${ }^{42}$ High correlations were also reported between hair nicotine concentration and the number of smokers living in the house. ${ }^{41} 42$ In a study of 72 young children, CPD to which a child was exposed was strongly correlated $(r=0.64)$ with hair nicotine levels. ${ }^{43}$ Woodruff et al, however, found a correlation of approximately 0.2 between the total number of cigarettes smoked in a child's presence in the past month and hair nicotine levels. ${ }^{44}$ One possibility for this lack of correlation is poor recall of the number of cigarettes smoked in the child's presence, as well as length of time to recall (1 month). In a multicountry study, hair nicotine levels among children and non-smoking women increased with increases in number of smokers living in the household, father's CPD and if smoking was permitted in the house. Additionally, children's hair nicotine increased if their mother smoked and her CPD, as well as with number of smokers sharing the child's bedroom. ${ }^{45}$ A study among non-smoking bar and restaurant workers showed higher hair nicotine levels with more sources of SHSe and higher values for those working in a bar. ${ }^{46}$

Between 1989 and 2009, 23 studies reported on urine cotinine and SHSe among adults and children (supplementary table S6). Four of these studies validated SHSe metrics in adults, with all but one study restricted to non-smokers. ${ }^{26} 353747$ Most of the studies found a low to strong correlation between SHSe and urine cotinine-to-creatinine ratio $(r=0.18-0.57)$. Correlation coefficients were strongest when the SHSe question was more specific. $^{26} 35$ Cummings et al found no-to-low correlation between urine cotinine and SHSe using various metrics, including total minutes of SHSe $(r=0.18)$, size, and ventilation properties of exposure location ( $r=0.24$ and 0.25 , respectively), and total number of SHSe $(r=0.23) .{ }^{47}$ O'Connor et al investigated SHSe in pregnant women by asking if they had SHSe for at least $1 \mathrm{~h}$ during the week they were monitored; the investigators found poor agreement with urine cotinine concentration $(\kappa=0.08){ }^{35}$

Of the 18 studies validating parents' report of SHSe in children using urine cotinine, exposure measurements were highly correlated with questions that were more specific and captured exposure intensity (supplementary table S6). Poor agreement was reported for children's SHSe in the home $(\kappa=0.33)$, in the same room as a smoker $(\kappa=0.11)$ and SHSe within the past 2 days $(\kappa=0.05-0.11)^{48} 49$ Willers et al, using an intensity scale based upon household members' smoking status, found strong a correlation with urine cotinine $(\mathrm{r}=0.61) .{ }^{50}$ Another study collecting information on the number of cigarettes smoked inside the house, as well as number of household smokers, also showed a strong correlation $(r \geq 0.59) .{ }^{42} \mathrm{CPD}$ and number of smokers in the household had moderate to strong correlations with cotinine measurements in several studies. ${ }^{15} 344^{4}{ }^{51-53} \mathrm{~A}$ study validated questions using infant's NNAL (4-[methylnitrosamino]-1-[3-pyridyl]-1-butanol) levels in urine. ${ }^{54}$ The correlation between cigarettes smoked, in the home and car, and NNAL concentrations was low.

Other methods of validation of SHSe questions include using cotinine in saliva, blood, plasma or serum (supplementary table S7). Studies validating adult's reported SHSe questions 
Table 3 Recommended questions for studies assessing secondhand smoke exposure (SHSe)

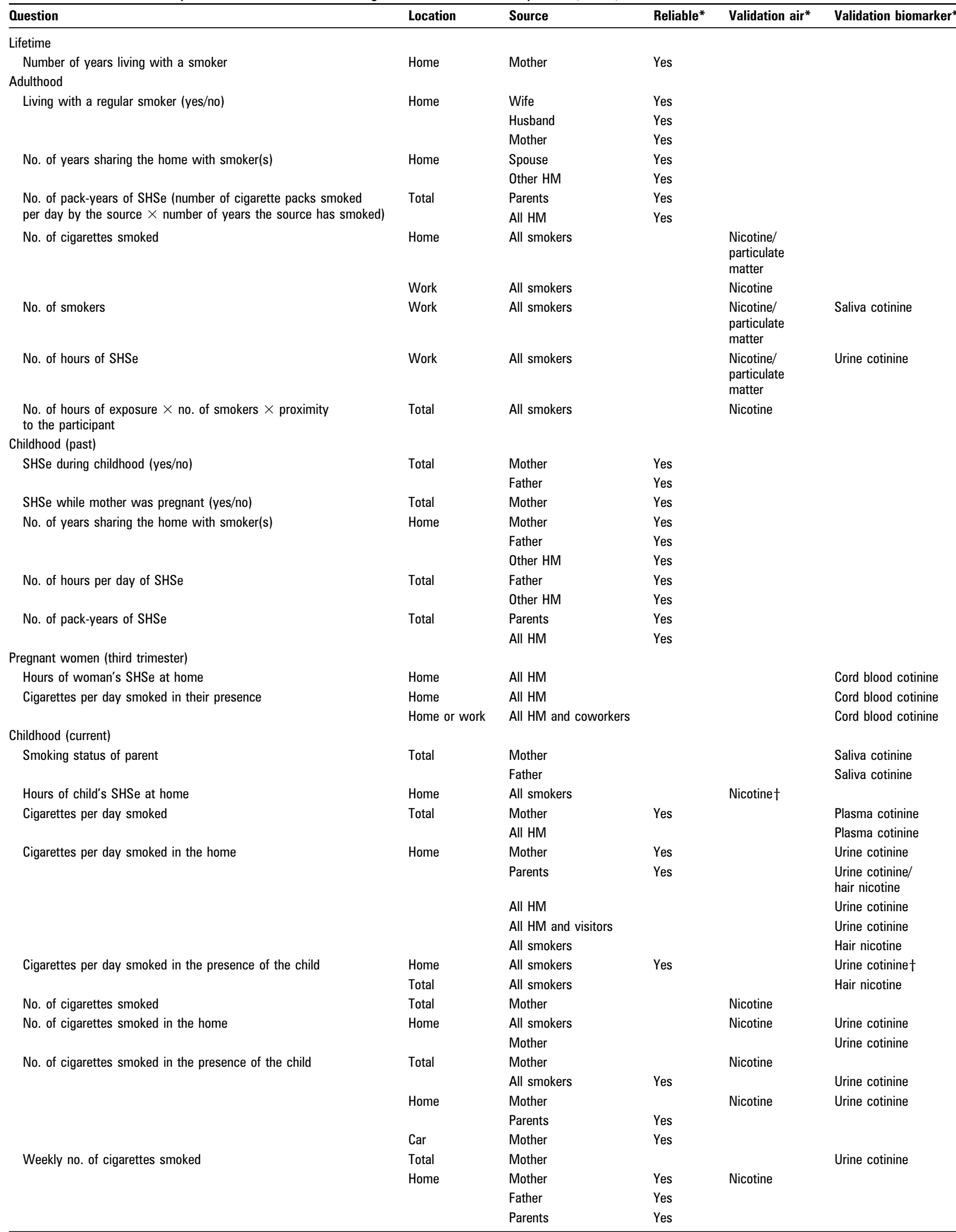


Table 3 Continued

\begin{tabular}{|c|c|c|c|c|c|}
\hline Question & Location & Source & Reliable* & Validation air* & Validation biomarker* \\
\hline \multirow{4}{*}{$\begin{array}{l}\text { Weekly no. of cigarettes smoked in the home in the } \\
\text { presence of the child }\end{array}$} & \multirow[t]{4}{*}{ Home } & Mother & Yes & & \\
\hline & & Father & Yes & & \\
\hline & & Parents & Yes & & \\
\hline & & All smokers & Yes & & \\
\hline Weekly no. of cigarettes smoked in the presence of the child & Total & All smokers & Yes & & \\
\hline \multirow[t]{2}{*}{ No. of smokers } & \multirow[t]{2}{*}{ Total } & All HM & & & $\begin{array}{l}\text { Hair nicotine/ } \\
\text { urine cotinine/ } \\
\text { serum cotinine }\end{array}$ \\
\hline & & All $\mathrm{HM}$ and visitors & & & Urine cotinine \\
\hline Cigarette butt counts in $24 \mathrm{~h}$ & Home & Mother & & & Urine cotinine \\
\hline Cigarette butt counts $\times$ hours spent in living room & Home & Father & & & Urine cotinine \\
\hline
\end{tabular}

${ }^{*} \kappa \geq 0.75$ or correlation coefficient $(r) \geq 0.50$.

†Reported by the smoking parent.

$H$, hair nicotine; HM, household members.

with saliva cotinine concentrations found moderate correlations with questions about total hours $(\mathrm{r}=0.34-0.45)$ or minutes $(\mathrm{r}=0.36)$ of SHSe. ${ }^{37} 55$ However, daily SHSe poorly agreed $(k \leq 0.15)$ with saliva cotinine. ${ }^{55}$ Validation studies of children's SHSe showed intermediate to strong correlations saliva cotinine levels with dichotomous reports of smoking in the home $(\kappa=0.44-0.47)$, and maternal and paternal smoking status $(\mathrm{r}=0.51-0.56) .{ }^{13}$ Paternal, maternal and total CPD were moderately to strongly correlated with children's plasma cotinine levels $(\mathrm{r}=0.40-0.59){ }^{15}$ Data from NHANES III obtained from 2516 children aged $4-16$ years showed a strong correlation $(r=0.57-0.73)$ between number of household smokers and serum cotinine. ${ }^{14} \mathrm{~A}$ study among pregnant women in their third trimester found strong correlations of cord blood cotinine levels with SHSe duration $(r=0.52)$ and CPD exposed $(r=0.52) .{ }^{57}$

\section{CONCLUSIONS}

Research on the health effects of SHSe has been conducted for over three decades, and exposure surveillance has been in place for over 20 years in the USA. ${ }^{58}$ A variety of instruments, although limited in their accuracy, have been developed and applied; they have proven useful for conducting aetiological studies and tracking SHSe of populations. Extensive experience with questionnaires allows us to (1) offer recommendations about use of instruments in various contexts; and (2) point to research needs. In table 3 , we present questions that meet reasonable standards for reliability and validity.

Researchers can assess SHSe with some confidence as study participants will answer reliably about childhood exposure to SHS by their mother (including if their mother smoked during pregnancy) or their father, and during adulthood if they live with a regular smoker. Accurate questions are still needed for adults living with their adult children, other relatives and nonrelatives that smoke. Study participants can consistently report the number of years of SHSe during their lifetime (source: mother), childhood (source: mother, father, or others) and adulthood (source: spouse or other household members). Hours per day of exposure during childhood (source: father or others) as well as pack-years of exposure (source: parents and all household members) and during adulthood (source: all household members and spouse) were also shown to be reliable questions.

For children's current exposure, researchers can obtain reliable answers when asking adults, and sometimes older children, about the amount of CPD the mother or their parents smoke, either overall or in the child's presence, as well as the number of cigarettes smoked by the mother, parents, or all smokers in the child's presence at home, outside of the home, or in a car. Research is needed to answer questions on current SHSe in children and adolescents, and to assess the reliability of responses from parents, older children and adolescents answering questions regarding SHSe (yes/no) and whether they live with a smoker, intensity of exposure and duration of exposure.

Assessments of exposure at home, in transport and in social settings are untested for reliability or validity. As more communities implement smoke-free legislation, the social norm for smoking inside the home or car will shift to formal smoking restrictions or bans. ${ }^{45} 60$ We encourage researchers to test these questions (table 3 ) in their studies to continue building a set of core questions for SHSe assessment. For example, FAMRI CoE investigators are determining the accuracy of a set core of questions, available for investigators at the FAMRI American Academy of Pediatrics Richmond Center of Excellence's website, for the assessment of children's SHSe.

Acknowledgements The authors would like to thank Nicole Ammerman and Charlotte Gerczak for their technical and editing assistance. The authors would also like to thank Drs Wael Al-Delaimy, Benjamin J Apelberg, David L Ashley, Neal L Benowitz, John T Bernert, Dana Best, Lara Gundel, Katharine Hammond, Stephen Hecht, Andrew Hyland, Sungroul Kim, Neil Klepeis and James Repace for their participation in the workshop.

Contributors EA-T organised and participated in the expert meeting, drafted and revised the paper. She is guarantor. JLE drafted and revised the paper. KMC, GTF, MFH, JDK, RMcM and JPW participated in the expert meeting, drafted and revised the paper. JMS initiated and organised the expert meeting and revised the draft paper.

Funding This work was supported by grants from the Flight Attendant Medical Research Institute to the Johns Hopkins Center of Excellence; the University of California, San Francisco Bland Lane Center of Excellence; and the American Academy of Pediatrics Julius B Richmond Center of Excellence. The funding organisation had no role in the preparation of the manuscripts.

Competing interests $\mathrm{KMC}$ has received payment as an expert witness in litigation against the tobacco industry.

Provenance and peer review Not commissioned; externally peer reviewed.

Data sharing statement Manuscript does not contain original data.

Open Access This is an Open Access article distributed in accordance with the Creative Commons Attribution Non Commercial (CC BY-NC 3.0) license, which permits others to distribute, remix, adapt, build upon this work non-commercially, and license their derivative works on different terms, provided the original work is properly cited and the use is non-commercial. See: http://creativecommons.org/licenses/by-nc/3.0/ 


\section{REFERENCES}

1. National Research Council N, Committee on Advances in Assessing Human Exposure to Airborne Pollutants. Human Exposure Assessment for Airborne Pollutants: Advances and Opportunities. Washington, DC: National Academy Press, 1991.

2. United States Department of Health and Human Services. The Health Consequences of Involuntary Exposure to Tobacco Smoke: A Report of the Surgeon General. Washington, DC: US Govt Printing Office, 2006.

3. Klepeis NE. An introduction to the indirect exposure assessment approach: modeling human exposure using microenvironmental measurements and the recent national human activity pattern survey. Environ health Perspect 1999;107 (Suppl 2):365-74

4. Samet JM, Jaakkola JJ. The epidemiologic approach to investigating outdoor air pollution. In: Holgate ST, Samet JM, Koren HS, et al, eds. Air Pollution and Health San Diego: Academic Press, 1999:431-60.

5. Matt GE, Bernert JT, Hovell MF. Measuring secondhand smoke exposure in children: an ecological measurement approach. J Pediatr Psychol 2008;33:156-75.

6. Matt GE, Quintana PJ, Destaillats $\mathrm{H}$, et al. Thirdhand tobacco smoke: emerging evidence and arguments for a multidisciplinary research agenda. Environ Health Perspect 2011:119:1218-26.

7. Williams JR. Medical ethics in contemporary clinical practice. J Chin Med Assoc 2005;68:495-9

8. Gilpin EA, Farkas AJ, Emery SL, et al. Clean indoor air: advances in California, 19901999. Am J Public Health 2002;92:785-91.

9. Guillemin F, Bombardier C, Beaton D. Cross-cultural adaptation of health-related quality of life measures: literature review and proposed guidelines. J Clin Epidemiol 1993:46:1417-32.

10. International Agency for Research on Cancer. IARC Handbooks of Cancer Prevention, Tobacco Control: Evaluating the Effectiveness of Smoke-Free Policies. Vol. 13. Lyon, France: International Agency for research on Cancer, 2009.

11. Hofstetter CR, Hovell MF, Jung KR, et al. The first puff: forces in smoking initiation among Californians of Korean descent. Nicotine Tob Res 2007;9:1277-86.

12. Hofstetter CR, Hovell MF, Irvin VL, et al. It's others, not the police: smoking, reprimand, and fines among adults of Korean descent in California. Health Psychol 2010;29:255-61.

13. Jarvis MJ, Russell MA, Feyerabend $C$, et al. Passive exposure to tobacco smoke: saliva cotinine concentrations in a representative population sample of non-smoking Schoolchildren. Br Med J (Clin Res Ed) 1985;291:927-9.

14. Wilkinson JD, Arheart KL, Lee DJ. Accuracy of parental reporting of secondhand smoke exposure: the National Health and Nutrition Examination Survey III. Nicotine Tob Res 2006;8:591-7.

15. Willers S, Axmon A, Feyerabend $\mathrm{C}$, et al. Assessment of environmental tobacco smoke exposure in children with asthmatic symptoms by questionnaire and cotinine concentrations in plasma, saliva, and urine. J Clin Epidemiol 2000;53:715-21.

16. Coughlin SS. Recall bias in epidemiologic studies. J Clin Epidemiol 1990:43:87-91.

17. Klepeis NE, Nelson WC, Ott WR, et al. The National Human Activity Pattern Survey (NHAPS): a resource for assessing exposure to environmental Pollutants. J Expo Anal Environ Epidemiol 2001;11:231-52.

18. Emerson JA, Hovell MF, Meltzer SB, et al. The accuracy of environmental tobacco smoke exposure measures among asthmatic children. J Clin Epidemiol 1995; 48:1251-9.

19. Gordis L. Epidemiology. 4th edn. Philadelphia: Elsevier, 2008

20. Sexton K, Callahan MA, Bryan EF. Estimating exposure and dose to characterize health risks: the role of human tissue monitoring in exposure assessment. Environ health Perspect 1995;103(Suppl 3):13-29.

21. Brown LS. Exposure assessment. In: Tardiff RG, Rodricks JV, eds. Toxic Substances and Human Risk. New York: Plenum Press, 1987:377-90.

22. Max W, Sung HY, Shi Y. Who is exposed to secondhand smoke? Self-reported and serum cotinine measured exposure in the U.S., 1999-2006. Int J Environ Res public health 2009;6:1633-48

23. Matt GE, Hovell MF, Zakarian JM, et al. Measuring secondhand smoke exposure in babies: the reliability and validity of mother reports in a sample of low-income families. Health Psychol 2000;19:232-41.

24. Coghlin J, Hammond SK, Gann PH. Development of epidemiologic tools for measuring environmental tobacco smoke exposure. Am J Epidemiol 1989;130:696-704.

25. Brownson RC, Alavanja MC, Hock ET. Reliability of passive smoke exposure histories in a case-control study of lung cancer. Int J Epidemiol 1993;22:804-8.

26. Coultas DB, Peake GT, Samet JM. Questionnaire assessment of lifetime and recent exposure to environmental tobacco smoke. Am J Epidemiol 1989:130:338-47.

27. Pron GE, Burch JD, Howe GR, et al. The reliability of passive smoking histories reported in a case-control study of lung cancer. Am J Epidemiol 1988;127:267-73.

28. Johansson A, Halling A, Hermansson G, et al. Assessment of smoking behaviors in the home and their influence on children's passive smoking: development of a questionnaire. Ann Epidemiol 2005:15:453-9.

29. Zakarian JM, Hovell MF, Sandweiss RD, et al. Behavioral counseling for reducing children's ETS exposure: implementation in community clinics. Nicotine Tob Res 2004:6:1061-74.

30. Hovell MF, Meltzer SB, Wahlgren DR, et al. Asthma management and environmental tobacco smoke exposure reduction in Latino children: a controlled trial. Pediatrics 2002:110:946-56.
31. Cummings KM, Markello SJ, Mahoney MC, et al. Measurement of lifetime exposure to passive smoke. Am J Epidemiol 1989;130:122-32.

32. Leaderer BP, Hammond SK. Evaluation of vapor-phase nicotine and respirable suspended particle mass as markers for environmental tobacco smoke. Environ Sci Technol 1991;25:770-7.

33. Marbury MC, Hammond SK, Haley NJ. Measuring exposure to environmenta tobacco smoke in studies of acute health effects. Am J Epidemiol 1993; 137:1089-97.

34. Berman BA, Wong GC, Bastani R, et al. Household smoking behavior and ETS exposure among children with asthma in low-income, minority households. Addict Behav 2003;28:111-28.

35. O'Connor TZ, Holford TR, Leaderer BP, et al. Measurement of exposure to environmental tobacco smoke in pregnant women. Am J Epidemiol 1995; 142:1315-21.

36. Thompson CV, Jenkins RA, Higgins CE. A thermal desorption method for the determination of nicotine in indoor environments. Environ Sci Technol 1989;23:429-35.

37. Coultas DB, Samet JM, McCarthy JF, et al. A personal monitoring study to assess workplace exposure to environmental tobacco smoke. Am J Public Health 1990;80:988-90.

38. Bolte G, Heitmann D, Kiranoglu M, et al. Exposure to environmental tobacco smoke in German restaurants, pubs and discotheques. J Expo Sci Environ Epidemiol 2008:18:262-71.

39. Eisner MD, Balmes J, Yelin EH, et al. Directly measured secondhand smoke exposure and COPD health outcomes. BMC Pulm Med 2006;6:12.

40. Wong GC, Bernaards CA, Berman BA, et al. Do children with asthma and their parents agree on household ETS exposure? Implications for asthma management. Patient Educ Couns 2004;53:19-25

41. Al-Delaimy WK, Crane J, Woodward A. Questionnaire and hair measurement of exposure to tobacco smoke. J Expo Anal Environ Epidemiol 2000;10:378-84.

42. Al-Delaimy WK, Crane J, Woodward A. Is the hair nicotine level a more accurate biomarker of environmental tobacco smoke exposure than urine cotinine? J Epidemio Community Health 2002;56:66-71.

43. Nafstad P, Botten G, Hagen JA, et al. Comparison of three methods for estimating environmental tobacco smoke exposure among children aged between 12 and 36 months. Int J Epidemiol 1995;24:88-94.

44. Woodruff SI, Conway TL, Edwards CC, et al. Acceptability and validity of hair collection from Latino children to assess exposure to environmental tobacco smoke. Nicotine Tob Res 2003;5:375-85

45. Wipfli H, Avila-Tang E, Navas-Acien A, et al. Secondhand smoke exposure among women and children: evidence from 31 countries. Am J Public Health 2008:98:672-9.

46. Okoli CT, Hall LA, Rayens MK, et al. Measuring tobacco smoke exposure among smoking and nonsmoking bar and restaurant workers. Biol Res Nurs 2007;9:81-9.

47. Cummings KM, Markello SJ, Mahoney M, et al. Measurement of current exposure to environmental tobacco smoke. Arch Environ Health 1990:45:74-9.

48. Boyaci H, Etiler N, Duman C, et al. Environmental tobacco smoke exposure in schoo children: parent report and urine cotinine measures. Pediatr Int 2006:48:382-9.

49. Callais F, Momas I, Roche D, et al. Questionnaire or objective assessment for studying exposure to tobacco smoke among asthmatic and healthy children: The French VESTA Study. Prev Med 2003:36:108-13.

50. Willers S, Hein HO, Jansson L. Assessment of environmental tobacco smoke exposure: urinary cotinine concentrations in children are strongly associated with the house dust concentrations of nicotine at home. Indoor Air 2004:14:83-6.

51. Wong GC, Berman BA, Hoang T, et al. Children's exposure to environmental tobacco smoke in the home: comparison of urine cotinine and parental reports. Arch Environ Health 2002:57:584-90.

52. Jurado D, Munoz C, Luna JD, et al. Environmental tobacco smoke exposure in children: parental perception of smokiness at home and other factors associated with urinary cotinine in preschool children. J Expo Anal Environ Epidemiol 2004;14:330-6.

53. Tyc VL, Lensing S, Vukadinovich CM, et al. Can parents of children with cancer accurately report their child's passive smoking exposure? Nicotine Tob Res 2009;11:1289-95.

54. Hecht SS, Carmella SG, Le KA, et al. 4-(Methylnitrosamino)-1-(3-Pyridyl)-1-butanol and its glucuronides in the urine of infants exposed to environmental tobacco smoke. Cancer Epidemiol Biomark Prev 2006;15:988-92.

55. Chen R, Tavendale R, Tunstall-Pedoe H. Measurement of passive smoking in adults: self-reported questionnaire or serum cotinine? J Cancer Epidemiol Prev 2002; 7:85-95

56. Emmons KM, Abrams DB, Marshall $\mathrm{R}$, et al. An evaluation of the relationship between self-report and biochemical measures of environmental tobacco smoke exposure. Prev Med 1994;23:35-9

57. Jedrychowski W, Perera F, Mroz E, et al. Fetal exposure to secondhand tobacco smoke assessed by maternal self-reports and cord blood cotinine: prospective cohort study in Krakow. Matern Child Health J 2009;13:415-23.

58. Hirayama T. Non-Smoking wives of heavy smokers have a higher risk of lung cancer: a study from Japan. Br Med J (Clin Res Ed) 1981;282:183-5.

59. Pirkle JL, Flegal KM, Bernert JT, et al. Exposure of the US population to environmental tobacco smoke: the Third National Heaith and Nutrition Exemination survey, 1988 to 1991. JAMA 1996;275:1233-40.

60. Jones MR, Navas-Acien A Yuan J, et al. Secondhand tobacco smoke concentrations in motor vehicles: a pilot study. Tob Control 2009;18:399-404.

. 